\title{
Isolation, Identification and Screening of Enterobacter cloacae KY231211 and Brevundimonas aurantiaca KY231210 for Biosurfactant Production
}

\author{
Arjun Karmakar ${ }^{1}$, Jyotsna Kiran Peter $^{1}$, Ankit Singla ${ }^{2}$ and Anita Raisagar ${ }^{1}$ \\ ${ }^{1}$ Sam Higginbottom University of Agriculture Technology and Sciences (SHUATS), \\ Prayagraj, Uttar Pradesh, India \\ ${ }^{2}$ Regional Center of Organic Farming, Ministry of Agriculture \& Frames Welfare, \\ Bhubaneswar, Govt. of India \\ *Corresponding author
}

\begin{abstract}
A B S T R A C T
Keywords

Biosurfactant, Brevundimonas aurantiaca KY231210, Enterobacter cloacae KY231211, PPBS, 16s rRNA

Article Info

Accepted:

17 March 2019

Available Online:

10 April 2019

In the present study on the basis of cultural, morphological, biochemical and 16s rRNA gene sequencing two rhizospheric bacteria were identified as Brevundimonas aurantiaca KY231210 and Enterobacter cloacae KY231211 and screened for their biosurfactant production potential by oil displacement assay, blood haemolysis assay and emulsification index with vegetable oils (soybean oil and sunflower oil) in different incubation period $(0$, 24, 48, 72 and 96h). In oil displacement assay, Enterobacter cloacae KY231211 and Brevundimonas aurantiaca KY231210 broth culture revealed positive oil displacement but Brevundimonas aurantiaca KY231210 showed highest displacement values than Enterobacter cloacae KY231211. Both cultures showed haemolysis on blood agar media. Soybean oil showed higher emulsification index with Enterobacter cloacae KY231211 culture while Brevundimonas aurantiaca KY231210 culture showed higher emulsification index with sunflower oil. Brevundimonas aurantiaca KY231210 revealed highest displacement values with Soybean oil. Brevundimonas aurantiaca KY231210 showed highest yield in biosurfactant production as compare to Enterobacter cloacae KY231211.

\section{Introduction}

Biosurfactant was first discovered as extracellular amphiphilic compounds of fermentation bacteria (Kitamoto et al., 2009). Biosurfactants are diverse groups of surface active molecules/chemical compounds synthesized by microorganisms (Desai and Banat 1997). These are amphiphilic biological compounds produced extracellularly or as part of the cell membrane by a variety of yeast,

bacteria and filamentous fungi (MataSandoval et al., 1999, 2000; Chen et al., 2007) from various substances including sugars, oils and wastes. All biosurfactant are amphiphiles, these amphiphilic compounds are produced on living surfaces, mostly on microbial cell surfaces, or excreted extracellularly. These are amphipathic molecules consist of two parts - a polar (hydrophilic) moiety and nonpolar (hydrophobic) group. A hydrophilic group
\end{abstract}


consists of mono-, oligo- or polysaccharides, peptides or proteins and a hydrophobic moiety usually contains saturated, unsaturated and hydroxylated fatty acids or fatty alcohols. A characteristic feature of biosurfactants is a hydrophilic-lipophilic balance (HLB) which specifies the portion of hydrophilic and hydrophobic constituents in surface-active substances. Both the hydrophilic and hydrophobic domains confer the ability to accumulate between fluid phases, thus reducing surface and interfacial tensions at the surface and interface respectively (Karanth et al., 1999). This property of biosurfactant makes them potential candidates for enhancing oil recovery (Sarkar et al., 1989).

Brevundimonas aurantiaca is a gram negative, rod shaped, aerobic bacteria. The Brevundimonas are a genus of proteobacteria. It has short wavelength flagella. It is motile and grows at $30^{\circ} \mathrm{C}$. It is mostly found in the rhizosphere region of the soil (Euzeby, 1997).

Enterobacter cloacae is a significant Gramnegative, facultative-anaerobic, rod shaped bacterium, frequently grown at $30^{\circ} \mathrm{C}$ on nutrient agar or broth. It bears peritrichous flagella. Enterobacter cloacae have been used in a bioreactor based method for the biodegradation of explosives and in the biological control of plant diseases (Dalben et al., 2008).

Biosurfactants, lead to an increasing interest as alternatives to chemical surfactants. Chemical surfactants are widely used in industries for cleanup of oil spills and heavy metal pollutants, enhancement of oil recovery, removal of oil sludge from storage tank, but these chemical surfactants are nonbiodegradable and toxic for environment; while if, biosurfactant will be used instead of chemical surfactant these are biodegradable, low toxic, eco-friendly, compatible with human skin, environmentally acceptable and have ability to produced from cheap substrates like vegetable oils such as sunflower and soybean oils, oil wastes from vegetable oil refineries and the food industry industrial oil wastes such as tallow, soapstock, marine oils, lard and free fatty acids, plant-derived oils such as jatropha oil, mesua oil, castor oils, ramtil oil and jojoba oil etc. The present study was conducted to demonstrate the isolation, identification and screening of biosurfactant producing bacteria and production of biosurfactant.

\section{Materials and Methods}

\section{Place of work}

The present study was conducted at PG Laboratory, Department of Microbiology Industrial Microbiology, Jacob Institute of Biotechnology and Bioengineering, Sam Higginbottom University of Agriculture, Technology and Sciences, Allahabad, UP during July 2015 to June 2016.

\section{Isolation of biosurfactant producing bacteria}

Biosurfactant producing bacteria Enterobacter cloacae KY231211 and Brevundimonas aurantiaca KY231210 were isolated from the rhizospheric soil collected from agricultural field of SHUATS. Serial ten-fold dilutions were prepared from the soil sample and $1 \mathrm{ml}$ of each dilution was added onto nutrient agar plates.

The plates were incubated for 24 hours at $30^{\circ} \mathrm{C}$. Colonies with different morphological appearances was selected from the countable plates and re-streaked on a new plate containing the same media to obtain pure colonies. The isolates obtained in this manner were maintained on nutrient agar slants. 


\section{Identification of bacterial isolates}

Isolates Enterobacter cloacae KY231211 and Brevundimonas aurantiaca KY231210 were identified by cultural, morphological, biochemical and molecular characterization. For colony morphology of isolates shape, edge, elevation, surface and pigmentation was recorded and for cellular morphology was cell shape and Gram staining was done. Biochemical characterization was done by using oxidase test, catalase test, indole test, citrate utilization assay, nitrate reduction test, urease test, esculin hydrolysis and sugar fermentation tests and molecular characterization was done by Sanger sequencing.

\section{Screening of isolates for biosurfactant production}

A loopful culture of Enterobacter cloacae KY231211 and Brevundimonas aurantiaca KY231210 was introduced to five $\mathrm{ml}$ Bushnell Haas broth in a flask and allowed to grow at $35^{\circ} \mathrm{C}$ for $10-15$ days at $160 \mathrm{rpm}$. Cells in the flask were harvested through centrifugation at $6000 \mathrm{rpm}$ for 15 minutes and supernatant was used as biosurfactant solution. The following tests were done to check the potency of biosurfactant production of isolates:

\section{Oil displacement assay}

$30 \mathrm{ml}$ of distilled water was taken in a Petriplate. $1 \mathrm{ml}$ of Sunflower oil was added to the centre of the plates containing distilled water. Then $20 \mu 1$ of the supernatant of the culture of isolates was poked into the oil drop.

An uninoculated oil drop in another petriplate served as a negative control. The biosurfactant producing organisms displace the oil (increases in diameter) and spread in water (Anandraj and Thivakaran, 2010).

\section{Blood haemolysis assay}

Hemolytic activity was tested using Blood agar plate. Blood agar medium was prepared using sheep blood (5\%) and blood agar base. Blood agar base was sterilized by autoclaving at $121^{\circ} \mathrm{C}$ at $15 \mathrm{lbs}$ pressure for $15 \mathrm{~min}$. The medium was poured into the plates and after solidify the medium; in center of each plate one well was bored with borer $(6 \mathrm{~mm})$. Then culture of Enterobacter cloacae KY231211 and Brevundimonas aurantiaca KY231210 were placed in wells in separate plate. The plates were kept for incubation at $30^{\circ} \mathrm{C}$ for 48-72 hours and observed for zone of clearance around the colonies. The clear zone indicated the presence of biosurfactant producing organisms (Carrillo et al., 1996).

Determination of emulsification index for selective vegetable oils by biosurfactant producing isolates

Emulsification is a process in which an emulsion is formed, an emulsion being liquid containing fine droplets of another liquid without forming a solution. Emulsification activity was performed by adding $2 \mathrm{ml}$ of Sunflower oil and Soybean oil to $2 \mathrm{ml}$ of aqueous solution of the isolates. The emulsion stability was determined at $0,24,48,72$ and $96 \mathrm{~h}$ of incubation. The emulsification index was generated as E0, E24, E48, E72, and E96 (EI) at $0,24,48,72$ and $96 \mathrm{~h}$ to check the stability of the emulsion formed (Anandraj and Thivakaran, 2010) and calculated by following formula:

Emulsification Activity $=$ Height of emulsion/Total height

$\mathrm{E} 0=$ emulsification index at $0 \mathrm{~h}$

E24=emulsification index after $24 \mathrm{~h}$

E48=emulsification index after $48 \mathrm{~h}$ E72=emulsification index after $72 \mathrm{~h}$ E96=emulsification index after 96h 
Production, extraction and partial purification of biosurfactant

Biosurfactant production was conducted in submerged batch mode. Bushnell Haas broth was used as the production medium for the biosurfactant.

The sterilized medium was seeded with 24$48 \mathrm{~h}$ old bacterial culture and kept in a shaking incubator maintained at $35^{\circ} \mathrm{C}$ for 10 days interval at $160 \mathrm{rpm}$. After 10 days the broth contained the biosurfactant that was further extracted at two sub stages viz. crude extraction of biosurfactant and solvent extraction of biosurfactant (partially purified biosurfactant).

\section{Crude extraction of biosurfactant}

The broth culture was centrifuged at 10,000 rpm for 30 minutes at $4^{\circ} \mathrm{C}$ and supernatant was collected. The pellet was discarded that contained the bacterial cell fractions.

The supernatant was collected as crude biosurfactant and was further purified through solvent extraction method.

\section{Solvent extraction (chloroform: methanol)}

The supernatant was subjected to acid precipitation by adding concentrated $\mathrm{HCl}$ (drop wise) to achieve a final $\mathrm{pH}$ of 2.0 and kept at $4^{\circ} \mathrm{C}$ overnight. The biosurfactant was extracted with mixed solvent system i.e. chloroform: methanol in 2:1 ratio.

\section{Results and Discussion}

\section{Isolation of biosurfactant producing bacteria}

Different bacterial isolates were isolated from rhizospheric soil and further identification was done.

\section{Identification of isolates}

Isolates were identified by as Brevundimonas aurantiaca KY23121 and Enterobacter cloacae KY23121 by cultural, morphological, biochemical and molecular characterization (16S rRNA sequencing).

Cultural, morphological and biochemical characterization of Enterobacter cloacae KY231211

The colony of Enterobacter cloacae KY231211 was white circular, with irregular margin, flat elevation and yellow to brown pigmentation. Enterobacter cloacae KY231211is Gram negative rods and Catalase positive, oxidase negative, citrate positive, Esculin hydrolysis negative and showed negative for salicin and ribose sugar fermentation (Table 1; Fig. 1).

Cultural, morphological and biochemical identification of Brevundimonas aurantiaca KY231210

The colony of Brevundimonas aurantiaca KY231210 was orange circular, with round margin, convex elevation and no pigmentation. It is a Gram negative rod and Catalase negative, citrate positive, Esculin hydrolysis negative and showed negative for salicine and ribose sugar fermentation (Table 1; Fig. 2).

Screening of Enterobacter cloacae KY231211 and Brevundimonas aurantiaca KY231210 for biosurfactant activity

\section{Oil displacement assay}

Oil displacement assay is a screening technique to identify biosurfactant activity by microorganism or by biosurfactants. Displacement of oil was measured for two different concentrations $v i z .10 \mu \mathrm{l} / \mathrm{drop}$ and 
$20 \mu 1 /$ drop oil. In each case displacement of oil was more by $20 \mu \mathrm{l}$ broth/drop oil. Brevundimonas aurantiaca KY231210 showed highest zone of oil displacement in comparison with Enterobacter cloacae KY231211 in all cases (Table 2).

\section{Blood haemolysis assay}

Blood haemolysis pattern of broth culture of Enterobacter cloacae KY231211 and Brevundimonas aurantiaca KY231210 were examined on Sheep Blood agar medium. Both broth culture (24 h old) of Enterobacter cloacae KY231211 and Brevundimonas aurantiaca KY231210 revealed $\beta$-haemolysis pattern on Blood agar plates. Zone of blood haemolysis was recorded higher with Enterobacter cloacae KY231211 in compared with Brevundimonas aurantiaca KY231210 (Table 3).

\section{Emulsification index}

Soybean oil gave highest emulsion at $0 \mathrm{~h}$ incubation in comparison to Sunflower oil at $0 \mathrm{~h}$ in case of Enterobacter cloacae KY231211, but in case of Brevundimonas aurantiaca KY231210 culture emulsification Sunflower oil gave highest emulsion at $0 \mathrm{~h}$ incubation in comparison to Soybean oil at $0 \mathrm{~h}$ respectively. Emulsification index was decreased with incubation time in all cases (Table 4; Fig 3).

\section{Production, extraction and partial purification of biosurfactant}

Biosurfactant was produced through submerged batch mode fermentation using 2\% Mustard oil and Sunflower oil as a SSCU supplemented to Bushnell Hass broth seeded with $\mathrm{Cfu} / \mathrm{ml}$ bacterial inoculums of Enterobacter cloacae KY231211 and Brevundimonas aurantiaca KY231210 followed by incubation $30 \pm 5^{\circ} \mathrm{C}$ for $15-20$ days at $160 \mathrm{rpm}$. Yield of PPBS was measured after solvent extraction and drying process (Fig. 4).

\section{Yield of biosurfactant in $\mathrm{g} / \mathrm{l}$ of production medium}

Yield was obtained after 15-20 days of incubation. Among the two isolates Brevundimonas aurantiaca KY231210 gave highest yield $(4.31 \mathrm{~g} / \mathrm{l})$ followed by yield of Enterobacter cloacae KY231211 (2.94g/l) (Fig. 5).

The single screening method is unsuitable for identifying all types of biosurfactant, and recommended that more than one screening method should be included during primary screening to identify potential biosurfactant producers (Kiran et al., 2010 and Satpute et al., 2008). Therefore, hemolytic activity assay, oil displacement assay, and emulsification activity measurement were used to screen the biosurfactant producer. If biosurfactant is present in supernatant, oil is displaced and a clearing zone is formed. The diameter of this zone on the oil surface correlates to surfactant activity. For pure biosurfactant a linear correlation between quantity of surfactant and clearing zone is obtained. The oil displacement assay was used as indicator for biosurfactant production for the screening of biosurfactant microorganisms (Anandaraj and Thivakaran, 2010; Priya and Usharani 2009; Urum et al., 2004).

Positive oil displacement was recorded in present study. This result was correlated with study of Bhat et al., (2015) and Rodrigues et al., (2006); whereas in blood haemolysis assay, $\beta$ haemolysis was recorded with both broth cultures. There is an association between hemolytic activity and surfactant production and because of this blood agar lysis is used for a primary method to screen 
biosurfactant production (Carrillo et al., 1996). Emulsification activities (E24) are one of the criteria to determine the potential of biosurfactant and determine the productivity of bio-emulsifier (Bonilla et al., 2005).

In the present study soybean oil and sunflower oil were used for emulsification and highest emulsification index was recorded in $0 \mathrm{~h}$ of incubation. Emulsification index was recorded in decreasing order when incubation periods were increased.

The production of biosurfactant from various carbon sources such as glycerol, glucose and hydrocarbons has been reported earlier by
Jayanti and Joshi (1992) (Fiebig et al., 1997; Haba et al., 2000; Raza et al., 2007). In present study mustard oil and sunflower oil were used for biosurfactant production.

These substrates are low priced, high in purity and as hydrophobic substrates they can possibly enhance the production of biosurfactant (Van Hamme et al., 2006). For extraction of biosurfactant centrifugation, sedimentation and organic solvent, chloroform and methanol was used (Peter et al., 2014). also reported the solvent extraction method for partially purification of biosurfactant and obtained highest yield of biosurfactant in Serratia spp.

Table.1 Taxonomic identification of Enterobacter cloacae KY231211 and Brevundimonas aurantiaca KY231210

\begin{tabular}{|c|c|c|c|}
\hline S.no. & Characteristics & Enterobacter cloacae & Brevundimonas aurantiaca \\
\hline & & KY231211 & KY231210 \\
\hline & & Cultural characteristics & \\
\hline \multirow[t]{2}{*}{1.} & Colour of colony on & White & Orange \\
\hline & Nutrient agar & & \\
\hline 2. & Shape of colony & Circular & Circular \\
\hline 3. & Elevation & Flat & Convex \\
\hline 4. & Margin & Irregular & Round \\
\hline 5. & Pigmentation & Yellow to brown & No pigmentation \\
\hline \multicolumn{4}{|c|}{ Morphological Characteristics } \\
\hline 1. & Gram's reaction & Negative & Negative \\
\hline \multirow[t]{2}{*}{2.} & Shape & Rod & Rod \\
\hline & & Biochemical characteristic & \\
\hline 1. & Catalase test & Positive & Positive \\
\hline 2. & Oxidase test & Negative & Negative \\
\hline 3. & Citrate test & Positive & Positive \\
\hline 4. & Esculin hydrolysis & Negative & - \\
\hline 5. & Indole test & - & Negative \\
\hline 6. & Nitrate reduction test & - & Negtaive \\
\hline \multirow[t]{2}{*}{7.} & Urease test & - & Negative \\
\hline & & $\begin{array}{l}\text { Carbohydrate } \\
\text { fermentation }\end{array}$ & \\
\hline 1. & Salicin fermentation & Negative & - \\
\hline 2. & Ribose fermentation & Negative & - \\
\hline 3. & Arabinose fermentation & - & Positive \\
\hline 4. & Xylose fermentation & - & Negative \\
\hline
\end{tabular}


Table.2 Oil displacement assay by broth culture

\begin{tabular}{|l|c|c|c|c|}
\hline \multirow{2}{*}{ Name of bacteria } & \multicolumn{4}{|c|}{ Zone of oil displacement $(\mathbf{m m})$} \\
\cline { 2 - 5 } & \multicolumn{2}{|c|}{ Sunflower oil } & Soybean oil \\
\hline Enterobacter cloacae KY231211 & $\mathbf{1 0} \boldsymbol{\mu l}$ & $\mathbf{2 0} \boldsymbol{\mu l}$ & $\mathbf{1 0} \boldsymbol{\mu l}$ & $\mathbf{2 0} \boldsymbol{\mu l}$ \\
\hline Brevundimonas aurantiaca KY231210 & 6.15 & 8.8 & 8.5 & 18 \\
\hline
\end{tabular}

Table.3 Blood haemolysis assay by broth culture

\begin{tabular}{|c|c|c|}
\hline Name of bacteria & Zone of haemolysis $(\mathbf{m m})$ & Type of haemolysis \\
\hline Enterobacter cloacae KY231211 & 5 & \\
\hline Brevundimonas aurantiaca KY231210 & 4.55 & \\
\hline
\end{tabular}

Table.4 Emulsification index for biosurfactant producing culture with Sunflower oil and Soybean oil

\begin{tabular}{|c|c|c|c|c|c|c|c|c|c|c|}
\hline \multirow[t]{2}{*}{ Oil } & & \multicolumn{3}{|c|}{$\begin{array}{l}\text { Enterobacter cloacae } \\
\text { KY } 231211\end{array}$} & \multirow[b]{2}{*}{$\mathbf{E}_{96}$} & \multicolumn{4}{|c|}{$\begin{array}{c}\text { Brevundimonas aurantiaca } \\
\text { KY231210 }\end{array}$} & \multirow[b]{2}{*}{$\mathbf{E}_{96}$} \\
\hline & $\mathbf{E}_{0}$ & $\mathbf{E}_{24}$ & $\mathbf{E}_{48}$ & $\mathbf{E}_{72}$ & & $\underset{0}{\mathbf{E}}$ & $\mathbf{E}_{24}$ & $\mathbf{E}_{48}$ & $\mathbf{E}_{72}$ & \\
\hline Sunflower & 22.5 & 18.75 & 14.75 & 10.75 & 6.5 & 32.5 & 27.75 & 22.5 & 18.75 & 12.5 \\
\hline Soybean & 55 & 47.5 & 40 & 35 & 25 & 22 & 19.75 & 17 & 14.35 & 9.5 \\
\hline
\end{tabular}

Fig.1 Phylogenetic tree of Enterobacter cloacae KY231211

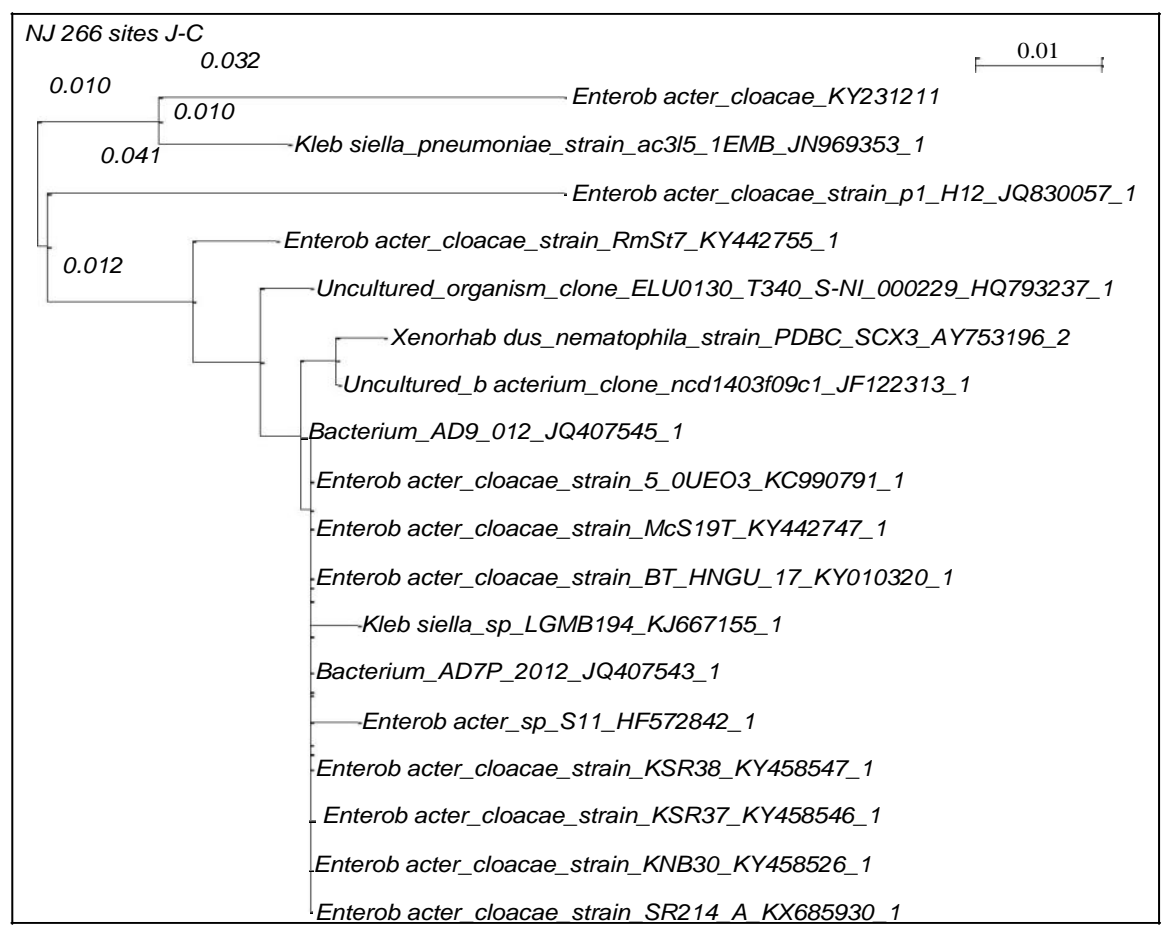


Fig.2 Phylogenetic tree of Brevundimonas aurantiaca KY231210

\begin{tabular}{|c|c|}
\hline \multirow{17}{*}{$\begin{array}{l}\text { NJ } 690 \text { sites J- } \\
\text { C } 0.021 \\
\begin{array}{l}0.011 \\
\end{array}\end{array}$} & -Brevundimonas_aurantiaca_KY231210 \\
\hline & Brevundimonas_sp_THG_T4_JX981953_1 \\
\hline & Brevundimonas_aurantiaca_strain_CICR_EMC1KU755452_1 \\
\hline & Brevundimonas_sp_224Fe_KM349213_1 \\
\hline & Brevundimonas_sp_dR5_16_HQ436453_1 \\
\hline & Brevundimonas_sp_strain_SX2S3S5_KX369407_1 \\
\hline & L_Uncultured_prokaryote_clone_Se1_7_GU208339_1 \\
\hline & Brevundimonas_aurantiaca_strain_ZJY_891_KP282766_1 \\
\hline & Brevundimonas_sp_SX2S1S8_KX289931_1 \\
\hline & Uncultured_bacterium_clone_WH_13_KM079066_1 \\
\hline & Uncultured_bacterium_clone_WH_3_KM079056_1 \\
\hline & Brevundimonas_aurantiaca_strain_CICR_EMA4_KU744945_1 \\
\hline & -Brevundimonas_aurantiaca_strain_CICR_EMA4_KU744945_1 \\
\hline & =Brevundimonas_sp_JXH_346_KR012334_1 \\
\hline & Uncultured_bacterium_clone_bacflank_0601KC607249_1 \\
\hline & _Brevundimonas_aurantiaca_LN835434_1 \\
\hline & Bacterium_VFL_b_EU195914_1 \\
\hline
\end{tabular}

Fig.3 (a) and (b) Emulsification index for biosurfactant producing culture with Sunflower oil and Soybean oil

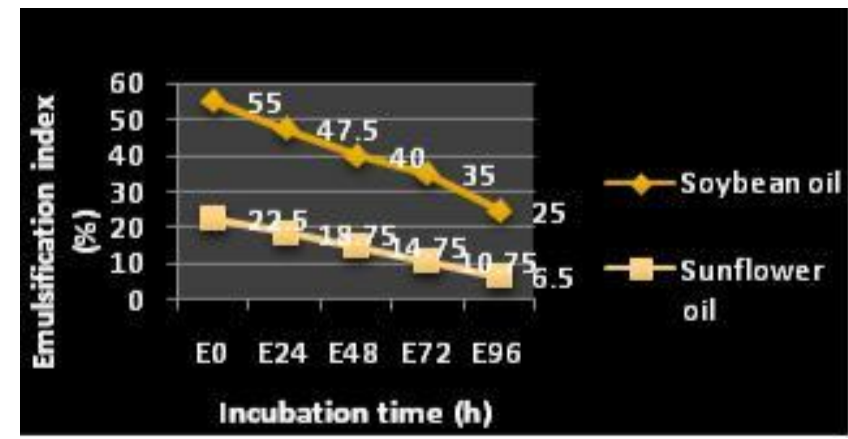

(a) Enterobacter cloacae KY231211

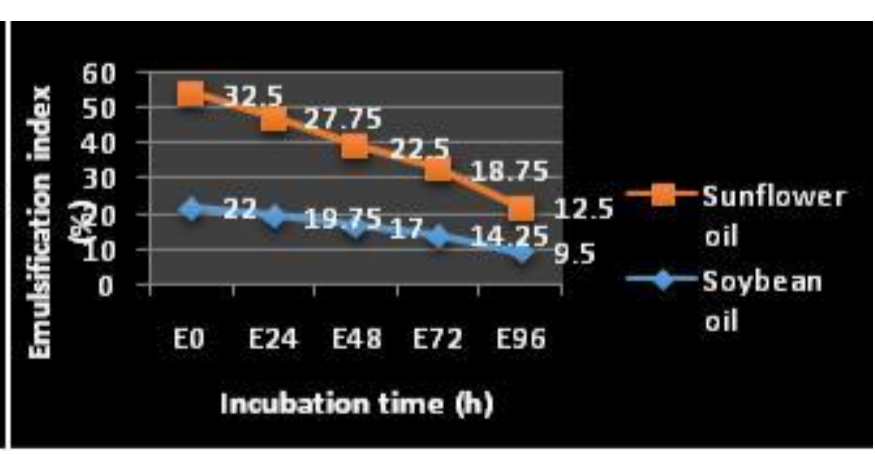

(b) Brevundimonas aurantiaca KY231210 
Fig.4 Production, extraction and partial purification of biosurfactant

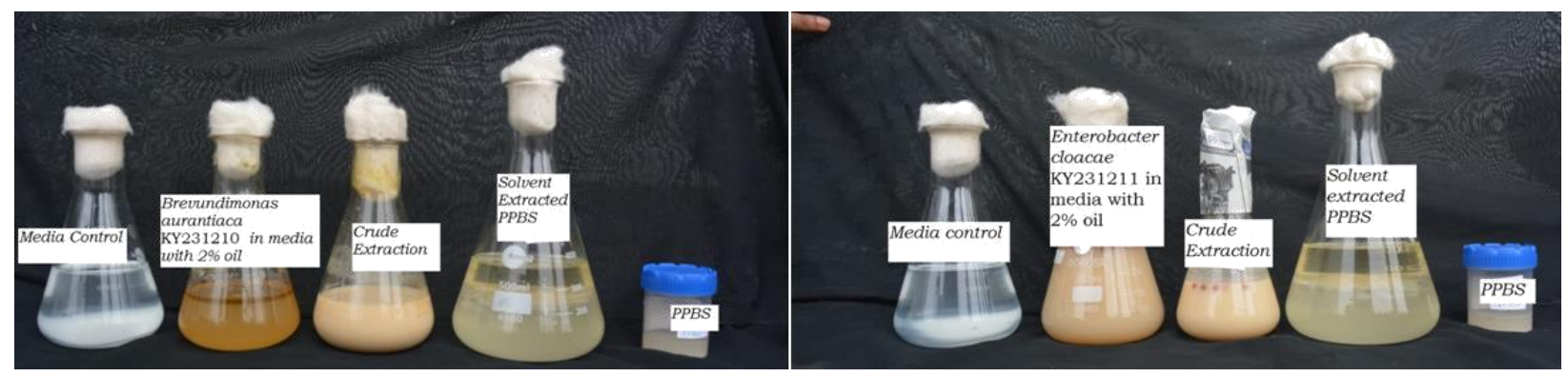

Fig.5 Yield of biosurfactant

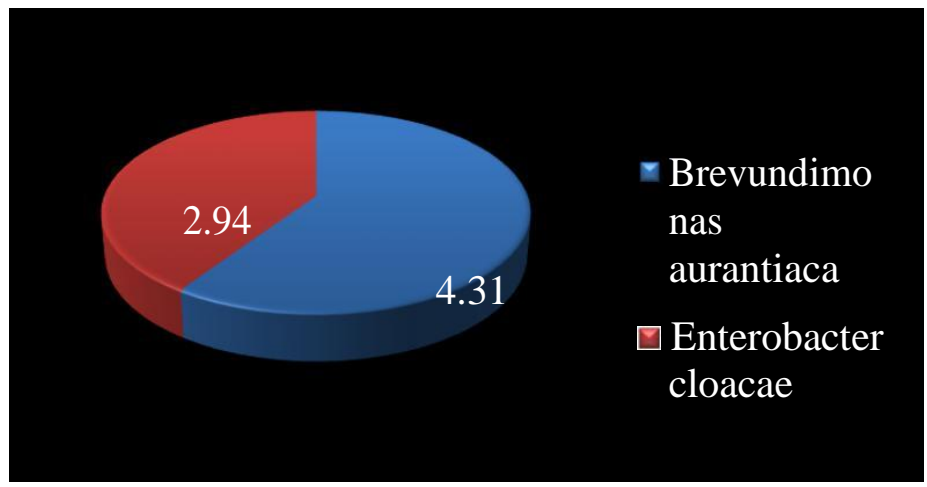

In conclusion, in this present study, biosurfactant is produced by using rhizospheric bacterial isolates i.e. Enterobacter cloacae KY231211 and Brevundimonas aurantiaca KY231210. Selected microorganisms showed positive result for all the method use for screening. Brevundimonas aurantiaca KY231210 is found to be higher yield of biosurfactant as compared to Enterobacter cloacae KY231211.

\section{References}

Anandaraj, B. and Thivakaran, P. 2010. Isolation and production of biosurfactant producing organism from oil spilled soil. Journal of Biosciences and Technology. 1(3): 120-126.

Bhat, R., Hegde, R., Dayamani, K.J., Hathwar, S., and Kush, A. 2015. Exploration on production of rhamnolipid biosurfactants using native Pseudomonas aeruginosa strains.
Journal of biological science and biotechnology. 4(2): 157-166.

Bonilla, M., Olivaro, C., Corona, M., Vazquez, A, and Soubes, M. 2005. Production and characterization of a new bioemulsifier from Pseudomonas putida ML2. Journal of Applied Microbialogy. 98: 456-463.

Carrillo, P., Mardaraz, C., Pitta-Alvarez, S. and Giulietti, A. 1996. Isolation and selection of biosurfactant producing bacteria. World Journal of Microbiology and Biotechnology. 12: 82-84.

Chen, Y.H., Del Genio, A.D. and Chen, J. 2007. The tropical atmospheric EI Nino signal in satellite precipitation data and a global climate model. Journal of Climate. 20: 3580-3601.

Dalben, M., Varkulja, G., Basso, M., Krebs, V.L., Gibelli, M.A., Van der Heijden, I., Rossi, F., Duboc, G., Levin, A.S. and Costa, S.F. 2008. Investigation of an outbreak of Enterobacter cloacae in a 
neonatal unit and review of the literature. The Journal of Hospital infection. 70(1): 7-14.

Desai, J.D. and Banat, I.M. 1997. Microbial production of surfactants and their commercial potential. Microbiology and Molecular Biology.61: 47-64.

Euzeby, J. P. 1997. List of bacterial names with standing in nomenclature: a folder available onthe internet. International Journal of Systematic Bacteriology. 47(2): 590-2.

Fiebig, R.D., Schulze, J., Chung, C. and Lee, S.T. 1997. Biodegradation of polychlorinated biphenyls (PCBs) in the presence of a bio-emulsifier produced on sunflower oil. Earth and Environmental Science. 8: 67-75.

Haba, E., Espuny, M.J., Busquets, M. and Manresa, A. 2000. Screening and production of rhamnolipids by Pseudomonas aeruginosa 47T2 NCIB 40044 from waste frying oils. Journal of Applied Microbiology. 88: 379-387.

Jayanti, K.L. and Joshi, S.R. 1992. Surfactant production by Pseudomonas stutzeri. Journal of Microbiology and Biotechnology. 7: 18-21.

Karanth, N.G.K., Deo, P.G., and Veenanadig, N.K. 1999. Microbial production of biosurfactants and their importance. Current Science. 77: 116-126.

Kiran, G.S., Thomas, T.A., Selvin, J., Sabarathnam, B. and Lipton, A.P. 2010. Optimization and characterization of a new lipopeptide biosurfactant produced by marine Brevibacterium aureum MSA13 in solid state culture. Bioresource Technology. 101: 23892396.

Kitamoto, D., Morit, T., Fukuoka, T., Konishi, M. A. and Imura, T. 2009. Self-assembling properties of glycolipid biosurfactants and their potential applications. Current Opinion in Colloid and Interface Science. 14 (5):
315-328.

Mata-Sandovel, J.C., Karns, J. and Torrents, A. 1999. High performance liquid chromatography method for the characterization of rhamnolipid mixtures produced by Pseudomonas aeruginosa UG2 on corn oil. Journal of Chromatography A. 864: 211-220.

Mata-Sandovel, J.C., Karns, J. and Torrents, A. 2000. Effect of nutritional and environmental conditions on the production and composition of rhamnolipids by Pseudomonas aeruginosa UG2. Microbiological Research. 155: 1-8.

Peter, J.K., Rao, A.K. and Kumari, R. 2014. Consortium based Biosurfactant development for degradation and emulsification of oils and Petroleum Hydrocarbons. International Journal of Engineering and Computer Science. 3(6): 6476-6490.

Priya, T. and Usharani, G. 2009. Comparative Study for Biosurfactant Production by Using Bacillus subtilis and Pseudomonas aeruginosa. Botany Research International. 2 (4): 284-287.

Raza, Z.A., Rehman, A., Khan, M.S. and Khalid, Z.M. 2006. Improved production of biosurfactant by a Pseudomonas aeruginosa mutant using vegetable oil refinery wastes. Earth and Environment Science. 18: 15-121.

Rodrigues, L.R., Banat, I.M., Teixeira, J.A. and Oliveira, R. (2006). Biosurfactants: potential applications in medicine. $J$. Antimicrob. Chemother., 57: 609-618

Sarkar, D.P., Morris, S.J., Eidelman, O., Zimmerberg, J. and Blumenthal, R. 1989. Initial stages of Influenza Hemaggulinin induced cell fusion monitored simultaneously by two Flourescent events: Cytoplasmic continuity and lipid mixing. The Journal of Cell Biology. 109: 113-122.

Satpute, S.K., Bhawsar, B.D., Dhakephalkar, 
P.K. and Chopade, B.A. 2008. Assessment of different screening methods for selecting biosurfactant producing marine bacteria. Indian Journal of Marine Science. 37: 243250.

Urum, K. and Pekdemir, T. 2004. Evaluation of biosurfactants for crude oil contaminated soil washing. Chemosphere. 57: 1139-1150.

Van Hamme, J.D., Singh, A. and Ward, O.P. 2006. Physiological aspects Part 1 in a series of papers devoted to surfactants in microbiology and biotechnology. Biotechnology Advances. 24: 604-620.

\section{How to cite this article:}

Arjun Karmakar, Jyotsna Kiran Peter, Ankit Singla and Anita Raisagar. 2019. Isolation, Identification and Screening of Enterobacter cloacae KY231211 and Brevundimonas aurantiaca KY231210 for Biosurfactant Production. Int.J.Curr.Microbiol.App.Sci. 8(04): 2328-2338. doi: https://doi.org/10.20546/ijcmas.2019.804.272 